\title{
Non-fatal asphyxiation and foreign body ingestion in children $0-14$ years
}

\author{
Anne E Altmann, Joan Ozanne-Smith
}

\begin{abstract}
Objectives-To examine the frequency and nature of non-fatal asphyxiation and foreign body ingestion injuries among children in the state of Victoria, Australia, and to identify possible areas for prevention.
\end{abstract}

Methods-For children under 15 years, all Victorian public hospital admissions, July 1987 to June 1995, due to asphyxiation or 'foreign body entering through other orifice' (which includes ingestions), were reviewed. Emergency department presentations due to asphyxiation and foreign body ingestion provided information on circumstances of, and the type of foreign bodies involved in the injuries.

Results-The childhood average annual admission rate for asphyxiation was 15.1 per 100000 . Food related asphyxiation peaked in infants under 1 year, and declined to low levels by 3 years. The main foods involved were nuts, carrot, apple, and candy. The rate of non-food related asphyxiation was relatively constant to 3 years of age and then declined by 6 years. Mechanical suffocation was less common. The annual admission rate for 'foreign body entering through other orifice' was 31.7 per 100000 . These injuries peaked in 2-3 year olds then gradually declined. About $80 \%$ of these foreign body admissions were ingestions, with coins being the major object ingested. Admission rates for these causes remained constant over the eight years. Asphyxiation resulted in a higher proportion admitted and longer hospital stays.

Conclusions-Prevention of suffocation and strangulation needs to focus on a safe sleeping environment and avoidance of ropes and cords, while foreign body asphyxiation and ingestion needs a focus on education of parents and child carers regarding age, appropriate food, risk of play with coins, and other small items. Legislation for toy small parts could be extended to those used by children up to the age of 5 years, and to other products marketed for children. Design changes and warning labels also have a place in prevention.

(Injury Prevention 1997; 3: 176-182)

Accident Research Centre, Monash 7niversity, Building Clayton, Victoria 3168 Australia

AE Altmann

J Ozanne-Smith

Correspondence to: Dr Altmann.
Choking and foreign body ingestion are frequent causes of injury in young children. They

Keywords: asphyxiation; ingestion; foreign body; epidemiology. are important not only for their frequency, buw also for their potential for resulting in death or severe complications, such as anoxic braino damage or oesophageal perforation. To date much of the literature on these injuries has focused on acute treatment or endoscopic $\vec{\omega}$ findings. Using an epidemiological approach,, we aim to examine risk factors involved in this group of injuries and address possible areas for $\omega$ prevention.

Following on from a review of fatal asphyx - बे iation deaths in Victorian children, ${ }^{1}$ this studys investigates non-fatal asphyxiation injuries in children. This enables an examination of similarities or differences in the epidemiology of fatal and non-fatal events, as well as pursuit of potential prevention strategies across differ- $\Omega$ ing severity levels. Foreign body ingestion injuries are also examined because of the manye similarities between them and foreign body inhalations in terms of mechanisms, age groups at risk, and object types.

Asphyxiation is defined as a lack of oxygeno in the blood due to interference with respiration. Causal subgroups of asphyxiation include $\stackrel{\varrho}{\rightarrow}$ suffocation, strangulation, and foreign body? inhalation (often termed choking). For the purpose of this study, 'foreign body ingestion? is the phrase used for injuries due to a foreign body within the gastrointestinal tract.

\section{Methods}

Data on non-fatal asphyxiations and foreign body ingestions in children were selected from? two sources in the state: public hospital admission data, collected in the Victorian Inpatient Minimum Dataset (VIMD); and? emergency department presentations, collected in the Victorian Injury Surveillance System (VISS).

The VIMD is under responsibility of the State Department of Human Services, and N records information on all admissions ton Victorian public hospitals since 1985. DataN are entered on a financial year basis, and wereo examined for the eight year period from Julye 1987 to June 1995 . Due to the changes over this period in recording information from? private hospitals, this study only examinest admissions to public hospitals.

From the VIMD, childhood asphyxiation and foreign body ingestion cases were selected $\stackrel{\Omega}{\Omega}$ according to the external cause of injury code? (E code) in the International Classification of Diseases 9th revision Clinical Modificationo (ICD-9-CM). ${ }^{2}$ The codes used for case selection were: food asphyxiation (E911); non-foodङ asphyxiation (E912); mechanical suffocation (E913) - bed/cradle (E913.0), plastic bag (E913.1), closed space (E913.2), falling earth/ 
cave-in (E913.3), other specified and hanging (E913.8), unspecified (E913.9); undetermined intent suffocation (E983); and foreign body entering through other orifice (E915). Procedures undertaken during a hospital admission were also accessed from the VIMD using ICD9-CM codes.

VISS data on emergency department presentations in children were collected at two regional hospitals over four years from July 1991 to June 1995, and at three metropolitan hospitals from 1989 to 1993 . As this is a subset of all presentations to Victorian emergency departments, the lack of denominator data makes rate calculation impossible. It is, however, a rich source of detailed information regarding the circumstances of injury.

Emergency department presentations for children under the age of 15 years were limited to asphyxiation and foreign body ingestion injuries. These were selected using a combination of variables, enabling case selection to be as similar to the $\mathrm{E}$ code definitions as possible, as well as limiting the foreign body injuries to those in the respiratory or gastrointestinal tract (excluding the nose and external mouth). A narrative text field was used for obtaining information on the type of foreign body or food ingested or inhaled, as well as for classifying the mechanical suffocation cases.

Due to differing causal mechanisms, asphyxiation due to drowning or submersion and fires were excluded from this study. For hospital admissions, the $\mathrm{E}$ code 915 'foreign body entering through other orifice' was used as this includes cases of foreign body within the gastrointestinal tract. For emergency department data, foreign bodies present at any other body locations were excluded. All cases of intentional injury (self inflicted or interpersonal violence) were excluded.

Population figures were downloaded from the Australian Bureau of Statistics. Annual estimated population figures were adjusted to December based figures, to match the financial year basis of hospital admission data. Average annual hosptial admission rates were calculated by dividing the number of admissions by the total estimated resident population for the relevant age and sex group over the eight year data collection period. Trends in rates were calculated using a Poisson regression model in SAS. ${ }^{3}$

\section{Results}

\section{HOSPITAL ADMISSIONS}

For children under 15 years of age, over the eight year period from July 1987 to June 1995, there were 1085 admissions to Victorian public hospitals from the specified causes of asphyxiation, an average annual rate of 15.1 per 100000 , and 2285 admissions due to 'foreign body entering through other orifice', a rate of 31.7 per 100000 . The majority of asphyxiation admissions (1032, 95.1\%) were caused by asphyxiation on food or non-food objects. There were similar numbers of asphyxiations on food as on non-food items, with an average annual hospital admission rate for each of approximately seven per 100000 (table 1).

There was a low number of mechanical asphyxiation cases, $53(4.9 \%)$, with a rate of 0.7 per 100000 . Most of these were due to beds or cots or hangings. There were no documented cases of asphyxiation due to plastic bags or in closed in spaces, nor any of undetermined intent.

Males were at slightly increased risk of admission, with a male to female ratio of 1.3:1 for asphyxiation injuries, and 1.2:1 for the foreign body group. The male predominance was most marked in the asphyxiation by food and mechanical suffocation groups where approximately $50 \%$ more boys were affected. The overall average annual admission rate due to asphyxiation for males was 16.7 , and for females was 13.4 per 100000 . For the cases due to 'foreign body entering through other orifice' the admission rate was 33.8 and 29.6 per 100000 for male and female children, respectively.

Children 0-4 years of age were at greatest risk. They accounted for $82 \%$ of asphyxiation and $57 \%$ of the foreign body admissions, with a rate of 36.8 and 53.7 per 100000 , respectively. Of mechanical suffocations, $68 \%$ also occurred in the young age group (table 1).

Infants under the age of 1 year had the highest risk of asphyxiation with $29.4 \%$ of asphyxiation admissions occurring in this age range, with a rate of 65.2 per 100000 . Their risk of 'foreign body' admission was lower, with a rate of 32.5 per 100000 , which was only $7 \%$ of all such childhood admissions. For infants, food related choking was the most common cause of asphyxiation, with a rate of 42.7 per 100000 . Bed and cradle related asphyxiations were almost exclusively a pro-

Table 1 Total number (\%) and average annual rate* of asphyxiation related hospital admissions by age group, children $0-14$ years, fuly 1987 to fune 1995, Victoria

\begin{tabular}{|c|c|c|c|c|c|c|c|c|}
\hline \multirow[b]{2}{*}{ Asphyxiation/foreign body } & \multicolumn{2}{|l|}{ All ages } & \multicolumn{2}{|l|}{$0-4$ years } & \multicolumn{2}{|l|}{$5-9$ years } & \multicolumn{2}{|l|}{$10-14$ years } \\
\hline & $\overline{N o(\%) \dagger}$ & Rate $^{*}$ & No (\%) $\ddagger$ & $\overline{\text { Rate }}$ & No (\%) $\ddagger$ & $\overline{\text { Rate }}$ & $\overline{N o(\%) \ddagger}$ & $\overline{\text { Rate }}$ \\
\hline $\begin{array}{l}\text { Food } \\
\text { Non-food } \\
\text { Mechanical suffocation } \\
\text { Bed/cradle } \\
\text { Falling earth/cave-in } \\
\text { Other specified/hanging } \\
\text { Unspecified } \\
\text { All asphyxiation } \\
\text { Foreign body entering through other orifice }\end{array}$ & $\begin{aligned} 510 & (47.0) \\
522 & (48.1) \\
53 & (4.9) \\
13 & (1.2) \\
4 & (0.4) \\
33 & (3.0) \\
3 & (0.3) \\
1085 & (32.2) \\
2285 & (67.8)\end{aligned}$ & $\begin{array}{l}7.1 \\
7.3 \\
0.7 \\
0.2 \\
0.1 \\
0.5 \\
0.04 \\
15.1 \\
15.2\end{array}$ & $\begin{array}{r}439(86.1) \\
418(80.1) \\
36(67.9) \\
12 \\
1 \\
21 \\
2 \\
893(82.3) \\
1302(57.0)\end{array}$ & $\begin{array}{l}18.1 \\
17.2 \\
1.5 \\
0.5 \\
0.04 \\
0.9 \\
0.1 \\
36.8 \\
53.7\end{array}$ & $\begin{aligned} & 37(7.3) \\
& 77(14.8) \\
& 4(7.5) \\
& 1 \\
&- \\
& 3 \\
&- \\
& 118(10.9) \\
& 673(29.5)\end{aligned}$ & $\begin{array}{l}1.6 \\
3.2 \\
0.2 \\
0.04 \\
- \\
0.1 \\
- \\
5.0 \\
28.3\end{array}$ & $\begin{aligned} & 34(6.7) \\
& 27(5.2) \\
& 13(24.6) \\
&- \\
& 3 \\
& 9 \\
& 1 \\
& 74(6.8) \\
& 310(13.6)\end{aligned}$ & $\begin{array}{l}1.4 \\
1.1 \\
0.5 \\
- \\
0.1 \\
0.4 \\
0.04 \\
3.1 \\
12.9\end{array}$ \\
\hline Total & $3370(100)$ & 31.7 & $2195(65.2)$ & 90.5 & $791(23.5)$ & 33.2 & $384(11.4)$ & 16.0 \\
\hline
\end{tabular}

^ Average annual rate per 100000 .

+ Column per cent.

+ Row per cent. 
blem for infants, who made up 12 of the 13 admissions from this cause.

Young children, 5-9 years, made up $10.9 \%$ of the asphyxiation, and $29.5 \%$ of the foreign body admissions. At this age asphyxiation was more likely to be due to non-food items. For young adolescent children, $10-14$ years, the risk is lower again for asphyxiation and foreign body admissions. Of the 74 asphyxiation cases in this age group, nine were hangings (or other specified means), and three involved falling earth or cave-ins.

Food related asphyxiation peaked in infants under 1 year, then rapidly declined to low levels by 3 years of age. Only $16.5 \%$ of cases occurred after 3 years. In contrast, the nonfood related asphyxiation admission rates were relatively constant at high levels from $0-3$ years, then declined to low levels by 7 years, with $27 \%$ of cases occurring after 3 years. 'Foreign body entering through other orifice' admission rates peaked in 2 year olds, then declined progressively with increasing age, with $53 \%$ of cases occurring after 3 years of age (fig 1).

Over the eight year period studied, there was no significant change in yearly admission rates to Victorian hospitals from asphyxiation or from 'foreign body entering through other orifice' (fig 2).

In general, asphyxiation and foreign body ingestion injuries result in short hospital stays. For asphyxiation cases, $73 \%$ spent one day or
Figure 1 Hospital admission rates for asphyxiation and 'foreign body entering through other orifice' by years of age, children $0-14$ years, Fuly 1987 to Fune 1995, Victoria.

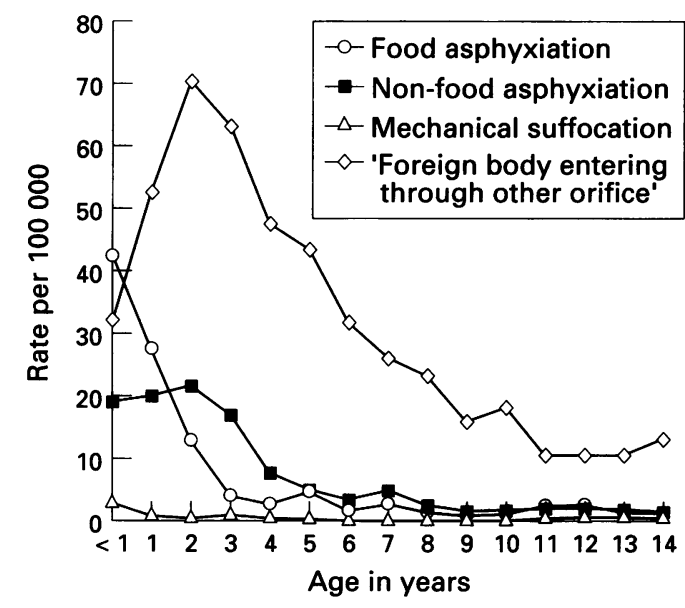

Figure 2 Annual rate of asphyxiation and 'foreign body entering through other orifice' hospital admissions, children 0-14 years, Ұuly 1987 to fune 1995, Victoria. less in hospital, and $95 \%$ one week or less. Extended hospital stay tended to be associated with foreign body inhalation and neurological complications of anoxia. For children admitteo. with foreign body ingestion, the hospital stay was generally shorter, with $91.3 \%$ remaining in hospital for one day or less, and the longes admission being 14 days.

While in hospital $625(57.6 \%)$ of the 10855 children with asphyxiation related injury underwent 838 procedures. Of children under $\widehat{\Omega}$ going a procedure, $58 \%$ did so for inhalation of non-food items into the airway, and $41 \%$ inhaled food. The most common procedures carried out on this group of children were removal of foreign bodies from the nose $(20 \%$ o of procedures), and laryngoscopy and bronchoscopy, with or without removal of foreign bodies ( $40.5 \%$ of procedures). Foreignbodies were removed from the oesophagus in $8.3 \%$ of children

For the 'foreign body entering through otherorifice' cases, $1870(81.8 \%)$ of the 22850 children underwent 2392 procedures. Of these procedures, $30.6 \%$ involved foreign body removal from the ear or nose, and $46.3 \%$ were upper gastrointestinal endoscopy, half of which involved removal of a foreign body from the oesophagus.

By examining the cases admitted to hospitalo from the emergency department (VISS) data (a small subset of admission data), it was calcu-ô lated that of those with a foreign body in theo gastrointestinal tract, nose, ears, or genitalia, $78.5 \%$ were confined to the gastrointestinal tract. This indicates that the E code 'foreign' body entering through other orifice' is largelyo made up of ingestions, with a smaller proportion of these children requiring endoscopic treatment.

\section{EMERGENCY DEPARTMENT PRESENTATIONS}

The VISS contains information on $82043^{\circ}$ children under 15 years of age who presented? to the defined emergency departments with an injury. Of this there were $393(0.5 \%)$ due to asphyxiation, and 1906 (2.3\%) due to a foreign body in the ear, nose, genitalia, or gastro-? intestinal tract, of which $861(1.0 \%)$ were dueo to a foreign body within the gastrointestinal tract.

Many of the foreign body ingestion emer- $N$ gency presentations $(55.9 \%)$ required little or N no treatment, while $15.7 \%$ required significanto treatment and $28.3 \%$ were admitted. Theo proportion of children that were subsequently admitted to hospital was higher for asphyxia-? tion related cases, $56.0 \%$, with only about one? third $(35.4 \%)$ requiring minor or no treatment. Admission frequency was highest in the 1 to $3 \stackrel{\mathbb{Q}}{\circ}$

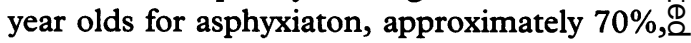
while for foreign body ingestions the admission proportion was relatively constant across age, $\varnothing$ at about one third.

As with the hospital admission data, there is a male predominance for all age groups in the? asphyxiation and foreign body ingestion presentation, $64.1 \%$ and $54.4 \%$ respectively. The emergency department presentations have a 
similar age distribution to the admissions. Asphyxiation presentations peaked in 1 year olds $(30.8 \%$ of asphyxiations and $16.6 \%$ of foreign body ingestions), while ingestions were highest in 2 and 3 year olds, and remained relatively frequent through the 5-9 year olds (table 2).

Asphyxiations and foreign body ingestions mainly occurred at a residential setting $(68.7 \%$ and $74.2 \%$, respectively). Only $3.1 \%$ in each group occurred at an education facility, with three $(0.8 \%)$ of the asphyxiations and five $(0.6 \%)$ of the ingestions being at daycare centres or kindergartens.

Useful narrative text was available in 369 $(93.9 \%)$ of the asphyxiation cases and 853 $(99.1 \%)$ of the foreign body ingestion cases. Of the 24 non-choking asphyxiations, four were due to smothering; 10 due to rope or cord strangulation; five due to head or neck entrapment; four due to carbon monoxide gas; and one was due to a cave-in (table 3). Smothering, due to facial occlusion, was a problem for infants, and typically bed related. Strangulation from ropes and cords occurred across the

Table 2 Number (\%) of emergency department presentations and proportion admitted to hospital due to asphyxiation and foreign body ingestion, by sex and age group, $0-14$ years

\begin{tabular}{lllll}
\hline Emergency department presentations & All ages & $0-4$ years & $5-9$ years & $10-14$ years \\
\hline Asphyxiation & $393(100)$ & $281(71.4)$ & $65(16.8)$ & $47(11.8)$ \\
$\quad$ Total (\%) & & & & \\
No (\%) of age group admitted to hospital & $220(56.0)$ & $171(60.9)$ & $29(44.6)$ & $20(42.6)$ \\
'Foreign body entering through other orifice' & & & & \\
$\quad$ Total (\%) & $861(100)$ & $569(66.1)$ & $209(24.3)$ & $83(9.6)$ \\
No (\%) of age group admitted to hospital & $244(28.3)$ & $164(28.8)$ & $51(24.4)$ & $29(34.9)$
\end{tabular}

Table 3 Emergency department presentations due to asphyxiation (non-foreign body), by mechanism and age group

\begin{tabular}{|c|c|c|}
\hline Mechanism $(n=24)$ & Age & Narrative text description of circumstances \\
\hline $\begin{array}{l}\text { Smothering } \\
(n=4)\end{array}$ & $\begin{array}{l}2 \mathrm{~m} \\
1 \mathrm{~m} \\
1 \mathrm{y}\end{array}$ & $\begin{array}{l}\text { Lying on floor with doona [duvet], pulled doona over self, } \\
\text { covering face } \\
\text { Caught wrapped in sleeping bag, stopped breathing } \\
\text { Sleeping in cot, found with } 12 \mathrm{~m} \text { cousin sitting on infant } \\
\text { While playing fell over and head first into muddy hole }\end{array}$ \\
\hline $\begin{array}{l}\text { Strangulation } \\
(n=10)\end{array}$ & $\begin{array}{l}8 \mathrm{~m} \\
1 \mathrm{y} \\
4 \mathrm{y} \\
4 \mathrm{y} \\
5 \mathrm{y} \\
5 \mathrm{y} \\
5 \mathrm{y} \\
12 \mathrm{y} \\
10 \mathrm{y} \\
11 \mathrm{y}\end{array}$ & $\begin{array}{l}\text { Sleeping, ribbon from toy wrapped around neck } \\
\text { Found hanging from venetian blind cord while mother out } \\
\text { hanging washing } \\
\text { Playing with cord with self locking around his neck, tightened } \\
\text { cord } \\
\text { Riding his bike, going too fast ran into rope caught around neck } \\
\text { Trying to make rope swing off clothes line, slipped on rocks, } \\
\text { strangled } \\
\text { While wriggling, head caught in doona ties which tightened } \\
\text { around throat } \\
\text { Child hung by pyjamas from wardrobe by cousin until choking } \\
\text { On 'flying fox' doing tricks, trick went wrong and momentarily } \\
\text { hanged } \\
\text { Sailing training, boat tipped over, rope around neck holding him } \\
\text { under water } \\
\text { Playing on bars with rope around neck and slipped off rope } \\
\text { tightening }\end{array}$ \\
\hline $\begin{array}{l}\text { Entrapment } \\
(\mathrm{n}=5)\end{array}$ & $\begin{array}{l}8 \mathrm{~m} \\
2 \mathrm{y} \\
3 \mathrm{y} \\
2 \mathrm{y} \\
5 \mathrm{y}\end{array}$ & $\begin{array}{l}\text { In high chair eating, slid under tray, got stuck, stopped } \\
\text { breathing } \\
\text { Caught by neck between horse float }{ }^{\star} \text { and two planks } \\
\text { Tractor rollover down embankment onto patient caught under } \\
\text { rear wheel } \\
\text { Climbed into car and ended up hanging from window by neck } \\
\text { Caught in car door when car rolled, car stopped, trapped } \\
\text { between door and } 44 \text { gallon drum }\end{array}$ \\
\hline $\begin{array}{l}\text { Carbon monoxide } \\
(\mathrm{n}=4)\end{array}$ & $\begin{array}{l}3 \mathrm{~m} \\
1 \mathrm{y} \\
10 \mathrm{y} \\
12 \mathrm{y}\end{array}$ & $\begin{array}{l}\text { Gas leak from hot water services possibly releasing carbon } \\
\text { monoxide into bedroom } \\
\text { Gas leak from hot water service possibly releasing carbon } \\
\text { monoxide into room } \\
\text { Bus had leaking exhaust, carbon monoxide poisoning } \\
\text { Passenger in car overcome by carbon monoxide fumes ? leaking } \\
\text { exhaust }\end{array}$ \\
\hline $\begin{array}{l}\text { Cave-in } \\
(\mathrm{n}=1)\end{array}$ & $12 y$ & $\begin{array}{l}\text { One digging tunnel in sand which collapsed, friend tried to dig } \\
\text { out }\end{array}$ \\
\hline
\end{tabular}

ॠ A trailer for two horses which is towed by a motor vehicle.

$\mathrm{m}=$ months; $\mathrm{y}=\mathrm{years}$. age groups and was often associated with unsafe play.

Coins were the most frequent foreign body ingested, accounting for $35.6 \%$ of all foreign bodies listed, while food was the major item $(60.9 \%)$ involved in asphyxiations (table 4$)$. By year of age, coins were again the predominant item ingested from 1-9 years. Where the denomination of the coin was stated $(70 \%$ of cases) it was those of smaller size that were more likely to be ingested. Fishbones were the major food to cause ingestion difficulties $(7.5 \%)$. Marbles were ingested by children from $1-9$ years of age, and accounted for $37 \%$ of the toy, and $3.8 \%$ of all ingestions. There were also significant numbers of button battery ingestions in all age groups.

For asphyxiations, the classic foods were represented. Forty nine $(14.3 \%)$ cases were due to nuts, 30 of which were peanuts. Carrots, apples, and candies were also significant causes of asphyxiation. Balloons were only listed in three ingestions and one asphyxiation. Fishbones were mentioned in $10.5 \%$ of casesthese were typically caught in the throat, and likely represent ingestion difficulties rather than asphyxiation.

\section{Discussion}

This study is limited primarily by data coding issues. Injury related hospital admissions are coded according to ICD-9 E code classification which does not allow delineation of foreign body ingestions per se, the code E915 'foreign body entering through other orifice' being used as proxy. Frequencies and rates, therefore, include admissions due to foreign bodies present in the ear and nose, and to a lesser extent in the rectum or vagina. By using a subset of data it was estimated that, although for a number of injuries the foreign body is in the nose or ear, in nearly $80 \%$ of cases it is within the gastrointestinal tract. Due to the possibility that the subset data were not completely representative, the admission data were not recalculated less the $20 \%$ of cases with foreign bodies in other locations.

Table 4 Foreign bodies (food and non-food items) resulting in asphyxiation and ingestion presentations to emergency departments, children $0-14$ years, Victoria; results are number (\%)

\begin{tabular}{lcc}
\hline Type of foreign body & $\begin{array}{c}\text { Asphyxiation } \\
(n=343)\end{array}$ & $\begin{array}{c}\text { Ingestion } \\
(n=853)\end{array}$ \\
\hline Coins & $26(7.6)$ & $304(35.6)$ \\
All foods & $209(60.9)$ & $166(19.5)$ \\
Fishbones & $36(10.5)$ & $64(7.5)$ \\
All nuts & $49(14.3)$ & $4(0.5)$ \\
Peanuts & $30(8.7)$ & $2(0.2)$ \\
Carrot & $13(3.8)$ & $2(0.2)$ \\
Apple & $12(3.5)$ & $5(0.6)$ \\
Candy & $9(2.6)$ & $14(1.6)$ \\
Hotdog/sausage & $3(0.9)$ & $6(0.7)$ \\
Pins/tacks/screws/nuts/washers & $15(4.4)$ & $73(8.6)$ \\
Toys (or parts of) & $19(5.5)$ & $86(10.1)$ \\
Marbles & $5(1.5)$ & $32(3.8)$ \\
Lego & $1(0.3)$ & $13(1.5)$ \\
Jewellery & $5(1.5)$ & $38(4.5)$ \\
Battery (button) & $-37(3.2)$ \\
Grass/leaves/stones & $12(3.5)$ & $8(0.9)$ \\
Pens and lids & $6(1.7)$ & $8(0.9)$ \\
Light bulb (or part of) & - & $5(0.6)$ \\
Button & $1(0.3)$ & $5(0.6)$ \\
Other & $50(14.6)$ & $133(15.6)$ \\
\hline
\end{tabular}


The VISS data (emergency department presentations) rely on injuries to be defined by the treating doctor and then the mechanism of injury to be coded by clerks (not medical record administrators). There is a possibility for misclassification of injuries, particularly with distinguishing between asphyxiation or ingestion. This can be seen with the large number of injuries caused by fishbones in the throat being coded as asphyxiation. The distinction is also difficult for objects which cause asphyxiation but are then swallowed. It follows that specific training on discrimination of cases involving the airway or the digestion tract for those responsible for coding injury data is necessary.

Due to the changes over the eight year period in recording information from private hospitals, this study only examines presentations to public hospitals. It is not thought that this would miss many children as the state's major paediatric hospitals are public, and the data will still include private patients being admitted to public hospitals. In addition, examination of available years of private hospital data revealed few cases. However, this exclusion may have resulted in a small underestimation of the admission rates.

The calculation of trends in rates of admission to public hospitals in Victoria needs to be examined with caution, due to changes in the funding mechanisms for Victorian hospitals in July 1993. Around this time, and subsequently, there may have been changes in the hospital's admission policies and practices contributing to an increase in the number of admissions. These changes have not, however, appeared to affect injury admissions reported here.

Strangulation and suffocation, compared with foreign bodies within the airway, have been found to be more frequent causes of fatal asphyxiation in Victoria. ${ }^{1}$ In contrast, non-fatal asphyxiation in children is dominated by food and foreign body inhalation, with only a small proportion of hospital admissions and emergency department presentations being due to suffocation or strangulation.

Foreign body ingestion, compared with asphyxiation, is a more frequent childhood problem, in terms of both hospital admissions and emergency department presentations. However, the proportion of cases admitted to hospital is lower, and the length of stay is shorter, than for injury due to asphyxiation, reflecting the relative severity of such injuries. The greater risk of injury due to a foreign body with the aerodigestive tract in younger children, particularly toddlers, is in concordance with many reports. ${ }^{4-13}$ The study found that although non-fatal asphyxiation is relatively uncommon after 4 years of age, foreign body ingestion injuries continue into the early teens.

Risk factors involved in childhood ingestion and inhalation injuries include: uncoordinated swallowing mechanisms in young children; inability to time swallowing and breathing, immature dentition (lack of molar teeth until 3-5 years); physical activity; the habit of exploring objects with the mouth; as well as congenital tracheo-oesophageal fistulae, and stricture or stenosis of the oesophagus secondary to this or other pathology. ${ }^{14}$ From these factors it follows that the objects causingchoking change with increasing age. Food related asphyxiation is particularly a problem $\overrightarrow{0}$ for the infants and 1 year olds, while by 2 years. of age non-food related asphyxiation resulted in nearly twice, and by 3 years of age, around fouro times, the admission rate. This reflects a child'so increasing ability to chew and swallow food, while at the same time objects in the environ-क्ष ment are still being explored with the mouth.

This review confirms peanuts as one of the most frequently documented food items to cause choking. ${ }^{4-7}$ 911-13 15 $^{15}$ Other foods such as $\overrightarrow{\vec{\omega}}$ other nuts, seeds, raw carrot and apple, candy, and hotdogs/sausages are also hazardous for young children. Although grapes have beenci mentioned in US studies, ${ }^{7}$ to date they have $\overrightarrow{ }$ not been found to be a problem in Australia, $O$ which may be due to different grape varieties. 9 As also noted by Schloss and Terraza, fish- $\overrightarrow{0}$ bones were a significant cause of food related ingestion injuries. ${ }^{10}$

Size, shape, and consistency are all impor- $-\frac{1}{3}$ tant determinants of an object's asphyxiation $\Phi$ risk. Small, spherical, cylindrical or round, and $\vec{\circ}$ pliable or conforming objects are more likely to@ cause fatal asphyxiation. ${ }^{81316}$ Combine these elements with the developmental factors of young children, and the risk of asphyxiation escalates. Small items may be toys or objectso not intended for child use. Although the serious asphyxiation risks of balloons has been well documented in the US, ${ }^{7817}$ this study found only one recorded case.

Foreign body related injury is not uncom mon in childhood, with many involving objects in the ear or nose, ${ }^{18}$ as seen in the hospital admission data. Ingestion of foreign bodies is also common in childhood, and although $a_{\mathbb{N}}^{\circ}$ large variety of objects can be represented, coins are invariably the most common object children swallow. ${ }^{813}$ 19-21 $^{1}$ In fact, emergency? department and hospital admission figures willo underestimate the true incidence of coin ingestions as many (half of known ingestions in one survey ${ }^{22}$ ) are managed at home or by
local doctors.

Changes in currency have been noted in the past to alter ingestion hazards for children. ${ }^{10}$ In October 1990 the Australian Mint ceased on issuing the one and two cent coins, and sincen this time they have been withdrawn from心 circulation. Apart from the Australian five cento coin, these were then the smallest coins in the currency. After this, one and two dollar coins $\overline{\mathbb{N}}_{\mathbb{N}}$ were introduced, both of which are small in $\stackrel{?}{?}$ size. Consequently, there has not been an 0 overall reduction in coin related ingestions, but rather a switch to ingestion of larger denomi- $\stackrel{\circ}{\Omega}$ nation, smaller sized coins. Reilly and Walter $\stackrel{\mathbb{Q}}{\varrho}$ found the frequency of ingestion of the different coin denominations matched the 8 distribution of coins in circulation, ${ }^{21}$ while the pattern of ingestion found in Victoria seems to be determined more by the size of the coin. Smaller sized coins were more frequently ingested, larger sized less frequently, with the largest coin, 50 cent, not featuring in any cases. 
Like coins, the size, shape, and availability of button batteries makes them commonly ingested objects, particularly among slightly older children, 5-12 years, ${ }^{23}{ }^{24}$ which may reflect the child's increasing exposure to battery-run products.

The morbidity from foreign body ingestion and inhalation has reduced since the introduction of endoscopic techniques for their removal. However, despite a perceived feeling that the community is well aware of the dangers of choking, there has been no significant decline in hospital admissions from this cause over the past eight years in Victoria.

\section{Implications for prevention}

As the mechanisms of non-fatal suffocation and strangulation asphyxiations are similar to the fatal cases previously reported, ${ }^{1}$ prevention strategies should incorporate education on the risks of blind cords near cots and unsafe play with ropes, as well as safe and age appropriate bedding for toddlers and infants. Safe design of nursery furniture is also critical.

In Australia, there are voluntary manufacturing standards outlining constructional and general safety requirements for children's toys. ${ }^{25}$ Some parts of this standard are also covered by federal legislation, namely the test for inhalation/ingestion hazard when the toy is intended for use by children 3 years or under. ${ }^{26}$ The cylinder for testing the size of the toy or toy part has a diameter of $3.2 \mathrm{~cm}$ and depth between $2.5 \mathrm{~cm}$ and $5.7 \mathrm{~cm}$, and is similar to that used in the 'small parts test fixture' (SPTF) test in the US.

This test for inhalation and ingestion risk has not proved totally successful in the US as children have choked on objects larger than this. ${ }^{8}$ In addition, many children over 3 years suffer choking injuries - one third of choking deaths in a US study, ${ }^{8}$ and about one third of non-food asphyxiation admissions in this study. From this type of information it has been concluded that the current standards are not sufficiently stringent, neither in size nor age limits. ${ }^{81327}$

Legislation in Australia allow toys with small parts to be sold if marketed to children older than 3 years. Combine this with the fact that toddlers often play with the toys of older siblings, ${ }^{28}$ and the potential for injury increases. The legislation and manufacturing standards could be extended to incorporate products marketed for children up to 5 years old. This would reduce injury directly to this age group, and also reduce injury indirectly to younger siblings exposed to the elder's toys. In addition, the regulations could be applied generically to all objects marketed at children (not solely toys), for instance, candy packaging and the inserts within candy.

Design changes are generally a preferable mechanism for injury prevention. For coin and food related ingestions and choking there are a few obvious solutions. A suggestion that a bittering agent be incorporated, exclusive of the mouthpiece, to balloon material, ${ }^{29}$ could be extended to other items such as marbles.
Obviously such a solution for nails, screws, pins, and the suchlike may not be acceptable for adults who tend to hold such objects in the mouth while working. Battery compartments in products could be made more secure to reduce accessibility, and a simply designed coin container for home use could be made to avoid loose coins being left about. Further investigation would first be necessary to identify more precisely the circumstances under which children gain access to coins at home.

Although warning labels alone are not felt to be sufficient in preventing injury, ${ }^{29}$ where there is no possibility for product modification, labelling can have a role in information dissemination, and may reduce the inappropriate purchasing of products for children. ${ }^{28}$ Labels are more likely to make an impact if they include a clear warning about the associated hazard, together with an age appropriateness statement. Labelling could certainly be considered for the packaging of high risk objects, such as peanuts and other nuts, hotdogs, candy, apples, carrots, button batteries, marbles, and balloons.

Education of parents and child carers is also necessary to prevent asphyxiation and foreign body ingestion injuries in children, as design changes are not always feasible. One successful widespread education program, undertaken in Israel during $1982-3$, focused on the choking dangers of nuts and seeds for young children. A significant reduction in hospital admissions from foreign body aspiration (36\%) was noted in the year after the campaign, and was sustained at this level until $1991 .^{30}$ This suggests that broad based education can aid in the reduction of choking injury.

Education should focus on knowledge about age appropriate foods for children, the substitution of risky foods with more appropriate foods, the importance of a quiet and supervised eating environment, the management of acute choking episodes, and the need to thoroughly debone fish when it is given to children. The risk of coin ingestion in young children, as well as toddlers, needs to be disseminated. Coins should not be given to children as play items, and other small objects not intended for child use need to be safely stored and disposed.

Asphyxiation and foreign body ingestion are significant causes of injury in children that need further attention for prevention. There is a scarcity of evaluated prevention programs and strategies, that address such injuries, in the published literature. Such information is obviously necessary to direct prevention efforts. A focus should include education of parents and child carers regarding age appropriate food, risk of play with coins and other small items, and acute management of choking. Legislation for toy small parts should be extended to children up to the age of 5 years and to other products marketed for children. Design changes and warning labels also have a place in prevention.

The authors wish to acknowledge the funding support for the MUARC product safety research program from the Victorian Health Promotion Foundation. 
1 Altmann A, Nolan T. Non-intentional asphyxiation deaths due to upper airway interference in children 0 to 14 years. Injury Prevention 1995; 1: 76-80.

2 The international classification of diseases 9th revision clinical modification (ICD-9-CM). Volume 3: procedures. Michigan USA: Edwards Brothers, 1988.

3 SAS Institute Inc. Statistical analysis system (SAS). Cary, NC: SAS Institute, 1990

$4 \mathrm{Mu} \mathrm{L}$, He P, Sun D. Inhalation of foreign bodies in Chinese children: a review of 400 cases. Laryngoscope 1991; 101: $657-60$.

5 Wolach B, Raz A, Weinberg J, Mikulski Y, Ari JB, Sadan N. Aspirated foreign bodies in the respiratory tract of children: eleven years experience with 127 patients. In f Pediatr Otorhinolaryngo 1994; 30: 1- 10 .

6 Mittleman RE. Fatal choking in infants and children. $A m \mathcal{F}$ Forensic Med Pathol 1984; 5: $201-10$

7 Harris CS, Baker SP, Smith GA, Harris RM. Childhood asphyxiation by food: a national analysis and overview. fAMA 1984; 251: $2231-5$.

8 Rimell FL, Thome A, Stool S, et al. Characteristics of objects that cause choking in children. $\mathscr{Y} A M A$ 1995; 274: $1763-6$

9 Laks Y, Barzilay $Z$. Foreign body aspiration in childhood. Pediatr Emerg Care 1988; 4: $102-6$.

10 Schloss MD, Terraza O. Introduction of a Canadian dolla coin has created a new health hazard for children. $f$ Otolaryngol 1993; 22: $428-30$

11 Linegar AG, Von Oppell UO, Hegemann S, et al. Tracheobronchial foreign bodies. Experience at Red Cross Children's Hospital, 1985-1990. S Afr Med 7 1992; 82: 164-7.

12 Brown TCK. Bronchoscopy removal of foreign bodies in children. Anaesth Intensive Care 1973; 1: $521-5$.

13 Reilly JS, Walter MA, Beste D, et al. Size/shape analysis of aeordigestive foreign bodies in children: a multi-institutional study. Am fOtolaryngol 1995; 16: $190-3$.

14 Kenna MA, Bluestone CD. Foreign bodies in the air and food passages. Pediatr Rev 1988; 10: 25-31.

15 Black RE, Johnson DG, Matlak ME. Bronchoscopic removal of aspirated foreign bodies in children. $\mathcal{F}$ Pediat Surg 1994; 29: $682-4$
16 Baker SP, Fisher RS. Childhood asphyxiation by choking or suffocation. $¥ A M A$ 1980; 244: $1343-6$.

17 Ryan CA, Yacoub W, Paton T, Avard D. Childhood death 5 from toy balloons. Am f Dis Child 1990; 144: 1221-4.

18 Denyer S. Foreign bodies: where do children put them? Health Visitor 1990; 63: 163-4.

19 Binder L, Anderson WA. Pediatric gastrointestinal foreigr body inestions. Ann Emerg Med 1984; 13:112 27.

20 Crysdale WS, Sendi KS, Yoo J. Esophageal foreign bodies im children: 15 year review of 484 cases. Ann Otol Rhind Laryngol $1991 ; 100: 320-4$

21 Reilly JS, Walter MA. Consumer product aspiration an $\bar{\phi}$ ingestion in children: analysis of emergency room report to the national electronic injury surveillance system. Ann Otol Rhinol Laryngol 1992; 101: 739-41.

22 Conners GP, Chamberlain JM, Weiner PR. Pediatric coin ingestion: a home-based survey. Am f Emerg Med 1995 13: $638-40$.

23 Sheikh A. Button battery ingestions in children. Pediate Emerg Care 1993; 9: 224 -9.

24 Litovitz $\mathrm{T}$, Schmits BF. Ingestion of cylindrical and buttor batteries: an analysis of 2382 cases. Pediatrics 1992; 89 batteries:

25 Standards Association of Australia. Children's toys (safet requirements). Part 1 general safety requirements, part constructional requirements. Australian Standard 1647 Sydney: Standards Australia, 1980

26 Consumer Affairs (Product Safety) (Children's toys) Rego ulations 1987. (Australia.)

27 Reilly JS. Prevention of aspiration in infants and young children: federal regulations. Ann Otol Rhinol Laryngot 1990; 99: $273-6$.

28 Langlois JA, Wallen BA, Teret SP, Bailey LA, Hershey JH Peeler MO. The impact of specific toy warning labels PAMA 1991; 265: 2848-50.

29 Baker SP, Halperin K. Designing the death out of balloons 7AMA 1995; 274: 1805 .

30 Sadam N, Raz A, Wolach B. Impact of community educational programmes on foreign body aspiration in Israel. Eur F Pediatr 1995; 154: 859-62.

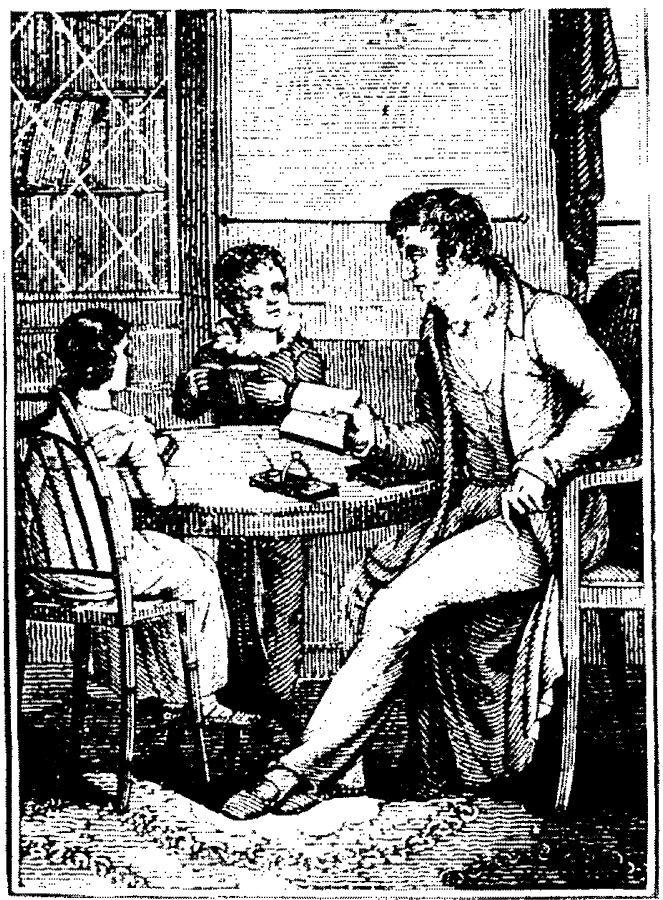

A Gentleman instruciing his Children, who spent their time in obeaining useful information, and therely escaped many accidents that might otherwise have Lctallen them.

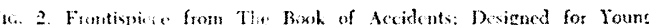
Chithen Vin Hisen, 1530 . 